\title{
Synaptogenesis of Electrical and GABAergic Synapses of Fast-Spiking Inhibitory Neurons in the Neocortex
}

\author{
Susanne Pangratz-Fuehrer and Shaul Hestrin \\ Department of Comparative Medicine, Stanford University School of Medicine, Stanford, California 94305
}

Parvalbumin-expressing fast-spiking (FS) cells are interconnected via GABAergic and electrical synapses and represent a major class of inhibitory interneurons in the neocortex. Synaptic connections among FS cells are critical for regulating network oscillations in the mature neocortex. However, it is unclear whether synaptic connections among FS interneurons also play a central role in the generation of patterned neuronal activity in the immature brain, which is thought to underlie the formation of neocortical circuits. Here, we investigated the developmental time course of synaptogenesis of FS cell in mouse visual cortex. In layer 5/6 (L5/6), we recorded from two or three FS and/or pyramidal (PYR) neurons to study the development of electrical and chemical synaptic interactions from postnatal day 3 (P3) to P18. We detected no evidence for functional connectivity for FS-FS or FS-PYR pairs at P3-P4. However, by P5-P6, we found that $20 \%$ of FS pairs were electrically coupled, and $24 \%$ of pairs were connected via GABAergic synapses; by P15-P18, $42 \%$ of FS pairs had established functional electrical synapses, and 47\% of FS pairs were connected via GABAergic synapses. FS cell GABAergic inhibition of pyramidal cells showed a similar developmental time line, but no electrical coupling was detected for FS-PYR pairs. We found that synaptogenesis of electrical and GABAergic connections of FS cells takes place in the same period. Together, our results suggest that chemical and electrical connections among FS cells can contribute to patterned neocortical activity only by the end of the first postnatal week.

\section{Introduction}

Parvalbumin (PV)-containing fast-spiking (FS) neurons are the most prominent GABAergic neurons in the neocortex (Kawaguchi and Kubota, 1997; Uematsu et al., 2008). In rodents, the birth date of FS cells peaks at embryonic day 17 (E17) (Hevner et al., 2004; Butt et al., 2005; Rymar and Sadikot, 2007). At postnatal day 1 (P1), inhibitory neurons are already present in the infragranular layers of the neocortex (Rymar and Sadikot, 2007).

In the newborn animal, these FS cells could, in principle, already be connected via electrical and/or GABAergic synapses, allowing them to form functional networks at birth. However, when during development FS cells form GABAergic and electrical connections has not yet been determined.

The functional connectivity of GABAergic neurons is of special interest as they have been implicated in generating patterned neuronal activity in both juvenile and adult neocortex (Jefferys et al., 1996; Ben-Ari, 2001; Klausberger et al., 2003; Ben-Ari et al., 2004; Hestrin and Galarreta, 2005; Cardin et al., 2009; Sohal et al., 2009). The coordinated activity of neocortical neurons in newborn animals is thought to be important for the normal develop-

Received Dec. 20, 2010; revised June 6, 2011; accepted June 9, 2011.

Author contributions: S.P.-F. and S.H. designed research; S.P.-F. performed research; S.H. contributed unpublished reagents/analytic tools; S.P.-F. and S.H. analyzed data; S.P.-F. and S.H. wrote the paper.

This work was supported by grants from the National Eye Institute and the National Alliance for Research on Schizophrenia and Depression (S.H.). We thank Josh Huang for contributing the G42 line. We thank Solange Brown for comments on this manuscript.

Correspondence should be addressed to Dr. Shaul Hestrin, Department of Comparative Medicine, Stanford University School of Medicine, Edwards Building, Room R314, 300 Pasteur Drive, Stanford, CA 94305-5342. E-mail: shestrin@stanford.edu.

DOI:10.1523/JNEUROSCI.6655-10.2011

Copyright $\odot 2011$ the authors $\quad 0270-6474 / 11 / 3110767-09 \$ 15.00 / 0$ ment of neocortical circuits (Katz and Shatz, 1996; Ben-Ari, 2001; Ben-Ari et al., 2004; Adelsberger et al., 2005; Cang et al., 2005; Moody and Bosma, 2005; Hanganu et al., 2006). The connectivity and synaptic properties of connections among GABAergic cells are thought to determine the intensity and frequency of their oscillatory activity (Jefferys et al., 1996; Bartos et al., 2002, 2007). There is evidence that both electrical and chemical synapses are involved in the generation of patterned activity in the immature neocortex (Peinado, 2001; Dupont et al., 2006). Previous reports have suggested that electrical synapses are extensive in the immature brain and that, during maturation, the prevalence of electrical synapses diminishes, whereas the prevalence of chemical synapses increases (Peinado et al., 1993a; Peinado, 2001; Montoro and Yuste, 2004; Sutor and Hagerty, 2005). These data suggest that the initial local circuits in the neocortex are based on electrical coupling, and that only later in the maturation process do chemical synapses become dominant (Montoro and Yuste, 2004). Furthermore, studies using paired recordings determined that electrical coupling is present among thalamic relay neurons and among inhibitory neurons in the thalamic reticular nucleus in newborn mice (Parker et al., 2009; Lee et al., 2010). However, whether electrical connections among FS cells are present in the postnatal neocortex and whether gap junctions form before GABAergic synapses in the newborn cortex has not been determined directly.

In this study we used transgenic mice that selectively express enhanced green fluorescent protein (EGFP) in parvalbuminpositive FS cells (Chattopadhyaya et al., 2004). We recorded from two or three EGFP-expressing cells simultaneously in patchclamp configuration and determined the cells' electrophysiolog- 
ical responses, synaptic connectivity, and synaptic properties. This approach allowed us to characterize the developmental time course of GABAergic and electrical connections among FS cells and between FS cells and pyramidal (PYR) neurons in the early postnatal period.

\section{Materials and Methods}

Slice preparation and cell identification. FS cells were identified in a mouse strain (G42) expressing EGFP under the control of the glutamic acid decarboxylase 67 (GAD67) promoter (Chattopadhyaya et al., 2004). P3 to P18 mice of both sexes were anesthetized by inhalation of isofluorane. Brains were removed and immersed in ice-cold solution containing the following (in mM): $87 \mathrm{NaCl}, 2.5 \mathrm{KCl}, 1.25 \mathrm{NaH}_{2} \mathrm{PO}_{4}, 7 \mathrm{MgSO}_{4}, 0.5 \mathrm{CaCl}_{2}$, $25 \mathrm{NaHCO}_{3}, 25$ glucose, and 75 sucrose, $\mathrm{pH} 7.4,315$ mOsm. Parasagittal cortical slices ( $300 \mu \mathrm{m}, 30^{\circ}$ angle) were obtained by using standard procedures (Galarreta et al., 2008). Initially, slices were incubated at $32-34^{\circ} \mathrm{C}$ for $25 \mathrm{~min}$ in the same solution. Subsequently, the slices were maintained for at least $25 \mathrm{~min}$ at room temperature in an oxygenated solution containing the following (in $\mathrm{mm}$ ): $125 \mathrm{NaCl}, 2.5 \mathrm{KCl}, 1.25 \mathrm{NaH}_{2} \mathrm{PO}_{4}, 1$ $\mathrm{MgSO}_{4}, 2 \mathrm{CaCl}_{2}, 26 \mathrm{NaHCO}_{3}, 20$ glucose, 4 lactic acid, 2 pyruvic acid, and 0.4 ascorbic acid, $\mathrm{pH} 7.4,315 \mathrm{mOsm}$ [artificial CSF (aCSF)]. Individual slices were transferred from the holding chamber to a submersiontype recording chamber, perfused with oxygenated aCSF at a rate of $2-4$ $\mathrm{ml} / \mathrm{min}$, and maintained at $32-34^{\circ} \mathrm{C}$. Recordings were obtained from layer 5/6 (L5/6) of the visual cortex. Fluorescent cells were visually identified using an upright microscope (Axioskop; Zeiss) illuminated with a Xenon lamp (150 W; Opti-Quip) and equipped with a $40 \times$ waterimmersion objective lens (Zeiss; NA, 0.8) and EGFP filters (XF100; Omega Optical). Selected fluorescent interneurons, as well as pyramidal cells, were visualized using infrared differential interference contrast video microscopy (C2400; Hamamatsu) and recorded using conventional patch-clamp techniques. All putative FS neurons were identified by their firing behavior in current clamp, as EGFP-positive FS cells showed characteristic discharges of high-frequency, nonadapting spike trains in response to near-threshold current injection (Kawaguchi, 1997).

Electrophysiology and data analysis. To test for connectivity via GABAergic and electrical synapses, simultaneous recordings were obtained from two or three FS and/or pyramidal cells using Axopatch 200B amplifiers (Molecular Devices). In total, we tested 278 possible connections among FS cells $(\mathrm{FS} \rightarrow \mathrm{FS}$ ) and 78 possible connections between FS cells and pyramidal neurons (FS $\rightarrow$ PYR). Patch electrodes (3-4 M $\Omega$ ) were filled with a solution containing the following (in $\mathrm{mM}$ ): $117 \mathrm{KCl}, 9$ HEPES, 4 MgATP, 3 GTP, 20 creatine phosphate, 0.18 EGTA, and 0.3\% biocytin, pH 7.3, $295 \mathrm{mOsm}$. GABAergic IPSCs were generally recorded in the presence of bath-applied DNQX (10 $\mu \mathrm{M}$, Sigma) by generating timed action potentials in each presynaptic cell candidate $(3 \mathrm{~ms}$ current pulse) while maintaining the postsynaptic neuron under voltage-clamp configuration at a holding potential $\left(V_{\mathrm{h}}\right)$ of $-70 \mathrm{mV}$. Synaptic responses appeared under these recording conditions as inward currents. The magnitude of the GABAergic conductance was estimated by dividing the average IPSC by the liquid junction-corrected driving force $(-75 \mathrm{mV})$. IPSPs at resting potential were recorded while maintaining both the presynaptic and postsynaptic cells under the current-clamp configuration. The connectivity via electrical synapses was tested by injecting prolonged pulses $(500 \mathrm{~ms})$ of hyperpolarizing current into each cell in turn and detecting a change in the membrane current of the electrically coupled neuron. The amplitude of the electrical coupling conductance was measured by dividing the current produced in one cell by a voltage step in the coupled cell. We used power spectral analysis (Igor, DSPPeriodogram operation; Wavemetrics) to determine the frequency of subthreshold membrane potential oscillations. The frequency of the subthreshold oscillations was indicated by a prominent peak in the power spectral plots (data not shown). The amplitude of the spikes and the amplitude of the afterhyperpolarization potentials (AHPs) were measured relative to the spike threshold. The duration of the AHPs was estimated by calculating the time interval between half-amplitude points of the AHPs (i.e., $\mathrm{AHP} t_{1 / 2}$ ). The voltage and current outputs were filtered at $5 \mathrm{kHz}$ and digitized at 16 bit resolution (ITC-18; Instrutech) with a sampling frequency of $10 \mathrm{kHz}$. The error due to the liquid junction potential was not corrected unless otherwise indicated. Access resistance of all recorded cells was not compensated and was monitored continually throughout each experiment; cells with a series resistance of $<18 \mathrm{M} \Omega$ and $<25 \%$ change for the duration of the experiment were used in our analysis.

Data are given as the mean \pm SEM. Statistical significance was tested using one-way ANOVA and independent Student's $t$ test, whereas the correlation coefficient $(R)$ was calculated with linear regression. Differences were considered significant if $p$ values were $<0.05$. Data acquisition and analysis were performed using Igor software (Wavemetrics).

Neuronal morphology. To reveal the morphology of the recorded neurons, $0.3 \% \mathrm{w} / \mathrm{v}$ biocytin was included in the pipette recording solution. Following the physiological recordings, the tissue was processed using standard techniques to visualize the neurons with diaminobenzidine. The axons and dendrites of well-stained neurons were reconstructed in three dimensions using a Neurolucida system (Microbrightfield) and a $\times 100$ oil-immersion objective (NA, 1.4; Zeiss). No correction was made for tissue shrinkage.

\section{Results}

Characteristic spiking patterns in immature FS cells

To identify FS cells in L5/6, we selected fluorescent cells in a transgenic mouse line expressing EGFP in parvalbumin-positive fast-spiking cells (Chattopadhyaya et al., 2004). In this GAD67GFP line (G42), the expression of GFP was detected as early as P0, and all GFP-positive cells became PV positive in the mature cortex (Chattopadhyaya et al., 2004). In the G42 line, about 50\% of parvalbumin cells also express EGFP (Chattopadhyaya et al., 2004). Thus, the EGFP-expressing cells that we studied may represent a subset of the parvalbumin cells. Our recordings from FS cells at P3-P6 showed that these cells display many of the characteristics of FS cells in adult cortex. Upon threshold current injections, FS cells at P3-P6 exhibited high-frequency discharges similar to the spiking behavior typical of adult FS cells (Kawaguchi, 1997; Galarreta and Hestrin, 2002; Tateno et al., 2004) (Fig. 1; Table 1). Repeating the same near-threshold current injection produced discharges exhibiting trial-to-trial variability that is also found in mature FS cells (Kawaguchi, 1997; Tateno et al., 2004; Towers and Hestrin, 2008) (Fig. 1 A). Moreover, previous work has established that FS cells may produce prominent intrinsic subthreshold oscillations (Fig. 1B) (Tateno et al., 2004; Towers and Hestrin, 2008). Data obtained from recordings at P2-P6 and P15-P18 showed significant differences in the frequency of subthreshold membrane potential oscillations (see Materials and Methods). We found that in immature FS cells, subthreshold oscillations had a range of $8-29 \mathrm{~Hz}$ (mean, $19.3 \pm 1.3 \mathrm{~Hz} ; n=11$ cells; P2-P6), whereas in more mature neurons the subthreshold oscillations had a range of $44-80 \mathrm{~Hz}$ (mean, $61.5 \pm 2.6 \mathrm{~Hz} ; n=$ 12 cells; P15-P18). Subthreshold oscillations were unaffected by synaptic neurotransmitter antagonists (DNQX and APV) (data not shown). In addition, we found that the duration of the AHP of P18 animals was shorter compared to that of P3 animals (Fig. 1C).

The membrane properties of FS cells progressively became more adultlike during the developmental time period that we studied (Table 1;Fig. 2). Figure $2 A$ shows the respective values for all age groups normalized to P3-P6, whereas Figure $2 B$ displays the developmental change in the discharge frequency and the $\mathrm{AHP}_{1 / 2}(n=15$ cells per age group). We found that the input resistance $\left(R_{\mathrm{i}}\right)$ of FS cells decreased by $60 \%$ between P3-P6 and P15-P18 (Fig. 2C). The afterhyperpolarization $\left(\mathrm{AHP} t_{1 / 2}\right)$ became faster by an average of $50 \%$ between $\mathrm{P} 3$ and $\mathrm{P} 18$, which was paralleled by an increase of up to $100 \%$ in spike 
A
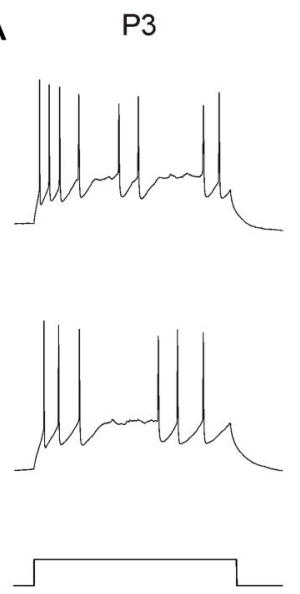

P18

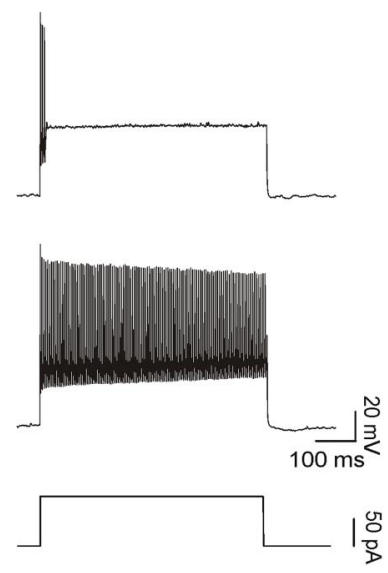

B

P3

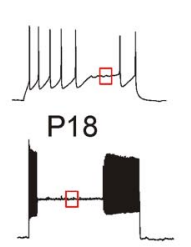

Subthreshold oscillations
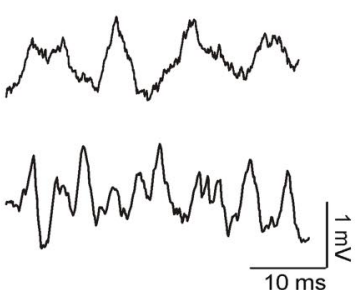

C

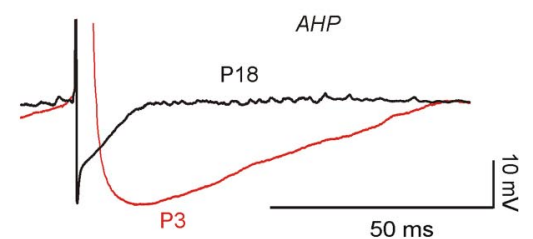

Figure 1. Spiking characteristics of FS cells at $\mathrm{P} 3$ and $\mathrm{P} 18 . A$, Comparison of FS cell firing pattern in response to near-threshold current injections obtained from $L 5 / 6$ mouse visual cortex at $\mathrm{P} 3$ ( 50 pA, $300 \mathrm{~ms}$; left) and P18 (400 pA, $300 \mathrm{~ms}$; right). Note that FS cells at P3 and P18 exhibited trail-to-trial variability in response to current injections. $\boldsymbol{B}$, Immature FS cells (P3; top) exhibited high-frequency subthreshold oscillations of the membrane potential, which is characteristic of mature FS cells (P18; bottom). C, Shorter AHP width at P18 compared to P3 (superimposed from the cell shown in $\boldsymbol{B}$ ).

Table 1. Electrophysiological properties of FS cells during development

\begin{tabular}{|c|c|c|c|c|c|c|}
\hline & FRQ (Hz) & HW (ms) & AHP (ms) & THD (pA) & $R_{\mathrm{i}}(\mathrm{M} \Omega)$ & $V_{m}(m V)$ \\
\hline P3-P6 & $27.6 \pm 2.9$ & $5.7 \pm 0.5$ & $19.9 \pm 2.5$ & $131.3 \pm 19.2$ & $213.7 \pm 22.1$ & $-60.6 \pm 2.0$ \\
\hline P7-P10 & $40.3 \pm 3.7^{*}$ & $2.5 \pm 0.4^{*}$ & $14.4 \pm 1.4$ & $150.3 \pm 13.1$ & $142.1 \pm 7.6^{*}$ & $-62.1 \pm 1.3$ \\
\hline P11-P14 & $50.6 \pm 5.2^{* *}$ & $1.5 \pm 0.4^{* *}$ & $13.7 \pm 1.5^{*}$ & $232.4 \pm 21.6^{*}$ & $95.7 \pm 7.4^{* *}$ & $-68.9 \pm 0.8^{*}$ \\
\hline P15-P18 & $64.6 \pm 13.1^{* *}$ & $0.9 \pm 0.2^{* *}$ & $10.2 \pm 1.2^{* *}$ & $348.7 \pm 17.2^{* *}$ & $84.4 \pm 4.6^{* *}$ & $-76.1 \pm 1.6^{* *}$ \\
\hline
\end{tabular}

All values are shown as means \pm SEM; $n=15$ per age group. Discharge frequency (FRQ) was calculated from total spikes elicited upon suprathreshold 500-ms-long current injections. Spike half-width (HW) and AHP were calculated as the difference between the action potential threshold and the most negative level reached during the repolarizing phase. TSH, Threshold.

${ }^{*} p>0.01 ;{ }^{* *} p>0.001$ (independent $t$ test comparisons).

A

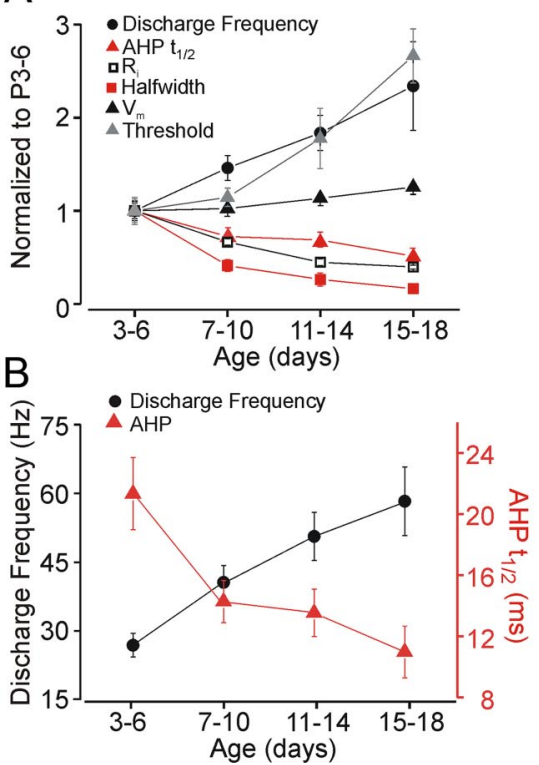

C $\square \mathrm{P} 15-18$
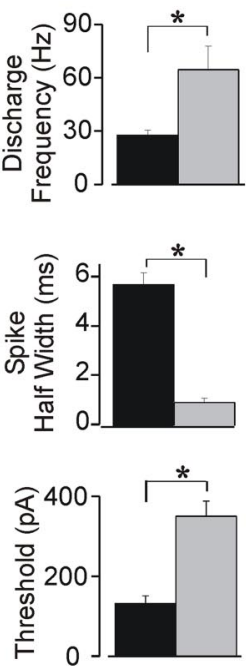

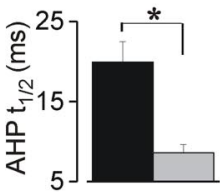

D P4
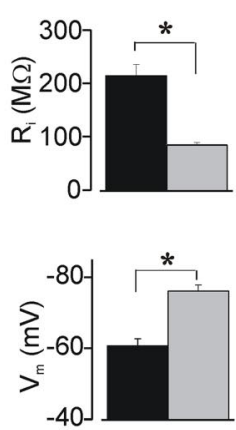

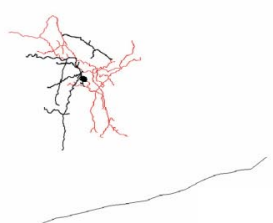

P16

Figure 2. Development of electrophysiological properties of FS cells. $A$, Developmental changes of FS cell electrophysiological properties (see Materials and Methods); data are normalized to P3-P6. B, The developmental increase in spike discharge frequency is paralleled by a shortening of the AHPt $t_{1 / 2}$. C, Statistically significant change of electrophysiological characteristics between P3-P6 and P15-P18. ${ }^{*} p<0.001$. D, Neurolucida tracings of GFP-positive GAD67-expressing neurons at P4 (top) and P16 (bottom). Somata and dendrites are shown in black; axons are shown in red.

discharge frequency during this time frame (Fig. 2A-C; Table 1). Furthermore, we found that at P3-P6, the mean resting potential $\left(V_{\mathrm{m}}\right)$ was more depolarized by an average of $16 \mathrm{mV}$ compared to FS cells from older animals. Finally, the spike half-width of immature FS cells was about sixfold longer compared to that in cells at P15-P18 (Fig. 2C). Neurolucida tracings of FS cells at different age groups display relatively sparse arborization of dendrites and axons in immature cells (Fig. 2D). 
The onset of functional GABAergic synapses among FS cells

It has been determined that, in the somatosensory cortex, the onset of feedforward inhibition onto spiny stellate cells in L4 occurs at P3-P9 (Daw et al., 2007). However, the developmental onset of functional inhibition among inhibitory neurons in the cortex has not been studied directly. Moreover, whether electrical and GABAergic connections among inhibitory neurons appear at the same developmental stage has not been determined.

To address this question, we used simultaneous triple and paired whole-cell recordings to evoke GABAergic responses from L5/6 FS interneurons between P3 and $\mathrm{P} 18$. We generated presynaptic action potentials with brief (2-3 ms) suprathreshold current injections in one FS cell and recorded the unitary responses from the other cells in an alternating pattern. Thus, we were able to test up to six directions from three pairs simultaneously. We recorded either unitary depolarizing IPSPs (uIPSPs) under current-clamp conditions (Fig. 3) or unitary hyperpolarizing IPSCs (uIPSCs) under voltage-clamp conditions (Fig. 4).

When recording from FS cells at $\mathrm{P} 3-$ $\mathrm{P} 4$, we did not identify unitary $\mathrm{GABA}_{\mathrm{A}} \mathrm{R}$ mediated responses ( $n=0 / 8$ pairs), and we found only one single functional GABAergic connection at P5 $(n=1 / 5$ pairs) (Fig. $3 A, D$ ). At $\mathrm{P} 6-\mathrm{P} 7$, synaptic connectivity was detected in 6 of 31 pairs (19.4\%). In the second postnatal week, we observed further increase in the rate of connectivity among FS cells. At P8-P11, we found GABAergic connections in 16 of 48 pairs $(33.3 \%)$. At P12-P14, 12 of 27 pairs $(44.4 \%)$ were connected, and at P15-P18 we identified GABAergic connections in 9 of 19 pairs (47.4\%) (Table 2; Fig. 3). Following the onset of GABAergic connections among FS cells, the probability of finding GABAergic connection was significantly correlated with the postnatal age $(r=0.72 ; p<0.005 ; n=130$ FS pairs tested) (Fig. 3). Furthermore, we found that the functional maturation of newly formed inhibitory synapses was also associated with a significant developmental increase in the amplitude of unitary GABA-mediated conductance (Fig. 4E; Table 2). We found that the magnitude of the GABAergic conductance increased from $295.7 \pm 39 \mathrm{pS}$ at P6-P7 to $701.6 \pm 119 \mathrm{pS}$ at P15P18 (Fig. 4E; Table 2).

Previous studies reported developmental changes in shortterm plasticity of inhibitory connections in the cerebellum (Pouzat and Hestrin, 1997). To test whether dynamics of GABAergic inhibition of FS cells change in the developing cortex, we estimated the paired-pulse ratio (PPR) (Fig. 4; Table 3). IPSCs among FS cell pairs exhibited short-term depression in all age groups (Fig. 4). However, for immature FS $\rightarrow$ FS synapses, the PPR was significantly smaller compared to rebetween $\mathrm{P} 5$ and $\mathrm{P} 18$ ).
FS-FS GABAergic synapses
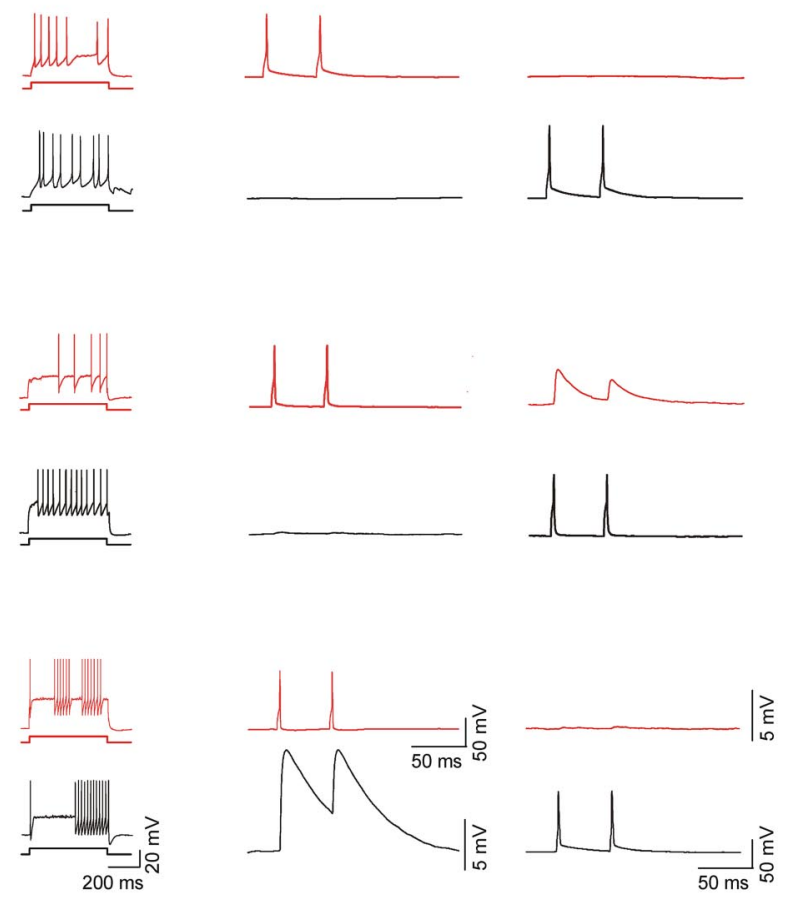

D

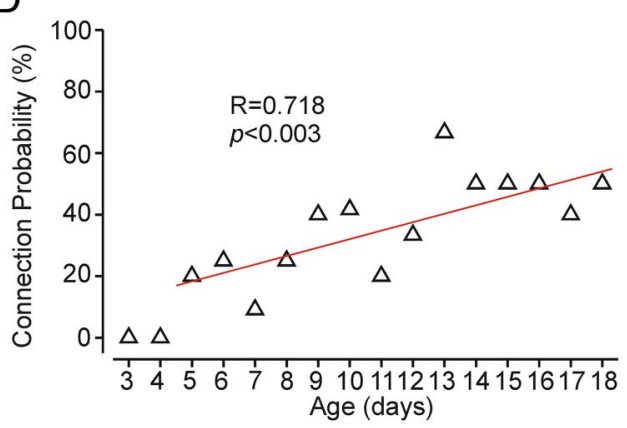

Figure 3. GABAergic connections among FS cells at P3, P6, and P14. Firing patterns of the respective two FS cells are shown on 政 3 we did not detect any GABA-mediated responses. B, At P6, FS1 and FS2 are connected via a unidirectional GABAergic 作 APs in FS1. D, Correlation between the connection probability and postnatal age $(r=0.72 ; p<0.005$; total of 130 pairs tested

sponses observed at P15-P18 (0.62 \pm 0.03 vs $0.91 \pm 0.05)$ (Fig. $4 A, B)$.

This developmental increase of the PPR was accompanied by significant reduction in IPSC failure rate. Unitary FS $\rightarrow$ FS synapses at P6-P7 exhibit a higher rate of failure compared to those of more mature FS cells, which rarely exhibited failures (21.2 \pm $5.7 \%$ vs $0.9 \pm 0.01 \%$ ) (Fig. $4 C, D$; Table 3 ).

\section{Does electrical coupling precede GABAergic signaling between FS cells?}

In juvenile and adult rodents, FS cells are connected by both GABAergic and electrical synapses (Galarreta and Hestrin, 1999; Gibson et al., 1999; Galarreta and Hestrin, 2002). It has been suggested that electrical coupling may organize cortical circuits before the development of chemical synapses (Peinado et al., 1993a; Peinado, 2001; Montoro and Yuste, 2004; Sutor and Hagerty, 2005). However, so far the relative onset of GABAergic 
A
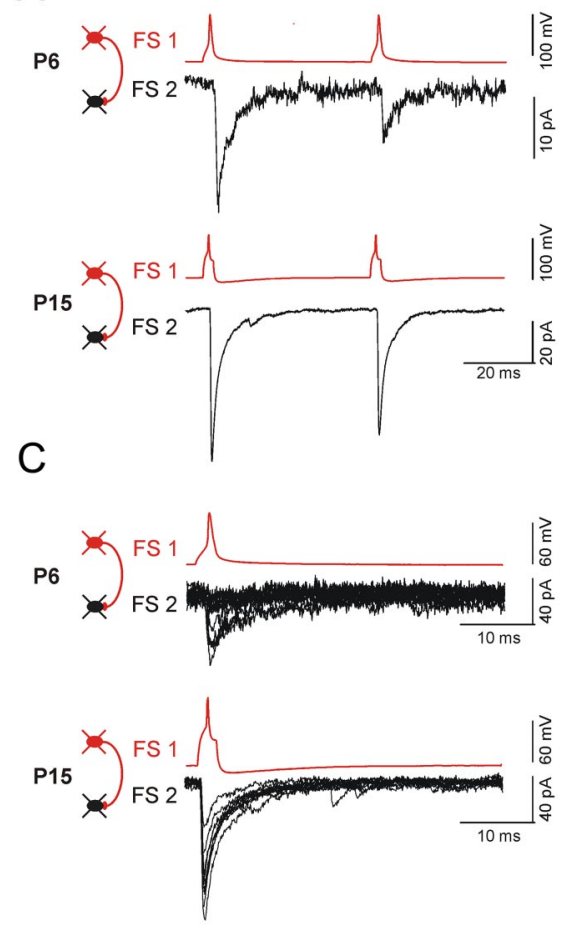

B

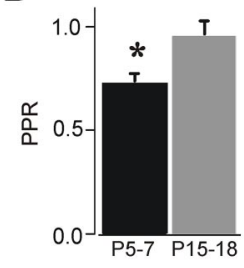

D

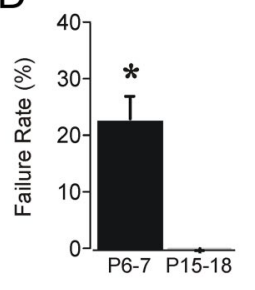

$E$

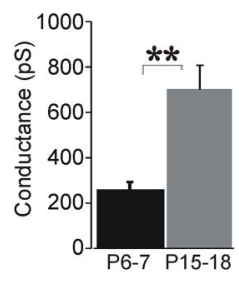

Figure 4. Developmental changes in the failure rate and paired-pulse ratio of inhibitory synapses among FS cells. A, Paired-pulse ratio of IPSCs is smaller at P6 (top) compared to P15 (bottom). $\boldsymbol{B}$, Analysis for each age group demonstrated significantly smaller PPR at P15-P18 compared with that at P3-P6 $\left({ }^{*} p<0.05\right)$. C, Evoked synaptic currents of $\mathrm{FS} \rightarrow \mathrm{FS}$ pairs demonstrated high failure rate at P6 ( $\boldsymbol{A}$, top) compared with IPSCs at P15-P18 ( $\boldsymbol{A}$, bottom). $\boldsymbol{D}$, Statistically significant decrease of the failure rate from $21.2 \%$ at P6 -P7 to 2.1\% at P15-P18 $\left({ }^{*} p<0.01 ; n=5\right)$. $\boldsymbol{E}$, Unitary GABA receptor-mediated conductances increased 2.5 -fold between $\mathrm{P} 5-\mathrm{P} 7$ (onset of connectivity) and P15-P17 ( ${ }^{* *} p<0.01 ; n=7-9$ pairs per age group).

Table 2. Electrical and chemical connectivity among $\mathrm{FS} \rightarrow \mathrm{FS}$ and $\mathrm{FS} \rightarrow \mathrm{PYR}$ pairs

\begin{tabular}{|c|c|c|c|c|c|c|}
\hline & \multicolumn{3}{|l|}{$\mathrm{FS} \rightarrow \mathrm{FS}$} & \multicolumn{3}{|l|}{$\mathrm{FS} \rightarrow \mathrm{PYR}$} \\
\hline & Prob. (\%) & $n$ & Conduct (pS) & Prob. (\%) & $n$ & Conduct (pS) \\
\hline \multicolumn{7}{|l|}{ P3-P5 } \\
\hline Electrical & 0 & $0(13)$ & NA & 0 & $0(6)$ & NA \\
\hline GABA & 7.7 & $1(13)$ & 174.33 & 0 & $0(6)$ & NA \\
\hline \multicolumn{7}{|l|}{ P6-P7 } \\
\hline Electrical & 25.8 & $8(31)$ & $271.8 \pm 16$ & 0 & $0(28)$ & NA \\
\hline GABA & 19.4 & $6(31)$ & $295.7 \pm 39$ & 21.4 & $6(28)$ & $155.3 \pm 16$ \\
\hline \multicolumn{7}{|l|}{ P8-P11 } \\
\hline Electrical & 33.3 & $16(48)$ & $395.9 \pm 41$ & 0 & 0 (17) & NA \\
\hline GABA & 33.3 & $16(48)$ & $401.3 \pm 82$ & 41.2 & $7(17)$ & $659.3 \pm 123$ \\
\hline \multicolumn{7}{|l|}{ P12-P14 } \\
\hline Electrical & 29.6 & $8(27)$ & $445.2 \pm 127$ & 0 & $0(16)$ & NA \\
\hline GABA & 44.4 & $12(27)$ & $653.0 \pm 178$ & 18.7 & $3(16)$ & $602.9 \pm 72$ \\
\hline \multicolumn{7}{|l|}{ P15-P18 } \\
\hline Electrical & 42.1 & $8(19)$ & $837.2 \pm 60$ & 0 & 0 (14) & NA \\
\hline GABA & 47.4 & $9(19)$ & $701.6 \pm 119$ & 50 & 7 (14) & $656.1 \pm 83$ \\
\hline
\end{tabular}

and electrical connections among inhibitory neocortical neurons has not been determined.

Thus, we next studied electrical coupling among FS cells during the first postnatal week (Fig. 5). To test for electrical coupling, we applied prolonged voltage steps $(200 \mathrm{~ms}, 30 \mathrm{mV})$ to one of the potentially coupled FS cells while current deflections recorded in voltage-clamp mode indicated electrical coupling between these two neurons. In P3-P5, animals we did not identify electrical coupling among FS $\rightarrow$ FS pairs ( 0 out of 13 pairs). The earliest

Table 3. Properties of GABAergic connections during development paired-pulse ratio and failure rate of GABAergic connections during development

\begin{tabular}{llllll}
\hline & \multicolumn{1}{l}{ FS $\rightarrow$ FS } & & & FS $\rightarrow$ PYR & \\
\cline { 2 - 3 } & PPR (ms) & Failure rate (\%) & & PPR (ms) & Failure rate (\%) \\
\hline P3-P6 & $0.62 \pm 0.03$ & $21.2 \pm 5.7$ & & $0.46 \pm 0.05$ & $35.3 \pm 3$ \\
P7-P10 & $0.81 \pm 0.07$ & $13.0 \pm 0.8$ & & $0.67 \pm 0.07$ & $16.2 \pm 2$ \\
P11-P14 & $0.77 \pm 0.06$ & $1.0 \pm 0.4$ & & $0.88 \pm 0.05$ & $8.3 \pm 3$ \\
P15-P18 & $0.91 \pm 0.05$ & $0.9 \pm 0.1$ & & $0.96 \pm 0.09$ & $4.0 \pm 0$ \\
\hline
\end{tabular}

All values are means \pm SEM.

time point at which we observed functional electrical synapses was P6, when 5 of 20 tested FS cell pairs (25\%) were coupled (Fig. $5 B, D)$. On average, we found an increase in coupling incidence up until P15-P18. Electrical coupling was identified in 8 of 31 pairs of P6-P7 animals (25.8\%), whereas at P8-P11 we found 16 of 48 pairs $(33.3 \%)$ to be coupled. By P15-P18, coupling was detected in 8 of 19 pairs $(42.1 \%$ ) (Fig. $5 C, D$ ).

In addition, we found that the strength of electrical coupling conductance increased threefold from $271.8 \pm 16 \mathrm{pS}$ at P6-P7 to $837.2 \pm 60 \mathrm{pS}$ at P15-P18 (Fig. 5E). Electrical coupling among $\mathrm{FS} \rightarrow$ FS pairs was always bidirectional, with similar conductance amplitude for both directions, although the coupling conductance varied significantly across different FS cell pairs.

Several FS $\rightarrow$ FS pairs were interconnected via both electrical and GABAergic synapses (data not shown). The probability of finding both types of connections increased with maturation. Only $3 \%$ of pairs were interconnected by both types of synapses at $\mathrm{P} 6-\mathrm{P} 7$, whereas at P15-P18, 30\% of cell pairs were mutually connected through both types of synapses. The probability of identifying GABAergic connections among electrically coupled pairs (40\%; 16 of 40 pairs) was not significantly different than the probability of identifying GABAergic connections among all FS pairs tested (31.9\%; 44 of 138 pairs).

\section{Electrical coupling is selective}

Previous studies have shown that FS cells are not electrically coupled to pyramidal cells in juvenile (2-3 week old) or adult rodents (Galarreta and Hestrin, 1999; Gibson et al., 1999; Galarreta and Hestrin, 2002). However, it has been reported that FS cells can form electrical synapses with excitatory neurons in L2/3 of somatosensory cortex of P12-P14 mice (Venance et al., 2000; Meyer et al., 2002). In older animals (P28), this type of connection disappears (Meyer et al., 2002). These data raise the possibility that the electrical coupling of FS cells is less selective in immature cortex compared with that of adult. Thus, we examined electrical coupling of FS cells and pyramidal neurons in neonatal cortical layer $5 / 6$. We performed simultaneous patchclamp recordings from two or three cells, testing a total number of 78 possible pairings between FS and pyramidal cells between P3 and P18. These data included 44 pairs at P3-P10. None of these pairs was found to be electrically coupled. We also tested whether pyramidal cells are electrically coupled in immature cortex. However, we did not identify electrical coupling among the tested pairs of pyramidal cells (22 pairs at P3-P10, 11 pairs at P11-P18). Thus, our data suggest that newly formed electrical synapses exhibit cell-type selectivity among FS cells.

\section{Development of inhibitory connections between FS cells and pyramidal neurons}

To investigate whether the FS cell network is able to affect pyramidal neurons during the first postnatal week, we recorded from pairs or triplets consisting of FS and pyramidal cells. Similar to 
GABAergic synapses among FS cells, we did not detect GABAergic signaling for $\mathrm{FS} \rightarrow$ PYR pairs (zero connections of five pairs) in animals younger than P5 (Fig. $6 A, D$; Table 2). Inhibitory synapses were first detected at $\mathrm{P} 6-\mathrm{P} 7$ in 6 of 28 pairs $(21.4 \%)$. By P $8-P 11$, we found that 7 of 17 pairs $(41.2 \%)$ were connected, and at P15-P18, 7 of $14 \mathrm{FS} \rightarrow$ PYR pairs $(50 \%)$ had established GABAergic synapses. Furthermore, we found that the newly formed inhibitory synapses exhibited developmental increase of the unitary conductance (Fig. 6E; Table 3). The mean increase was 4.2-fold, from $155.3 \pm 16 \mathrm{pS}$ at P6-P7 to $656.1 \pm 83 \mathrm{pS}$ at P15-P18 ( $n=6$ pairs per age group). We also estimated the PPR and failure rate of inhibition between FS and pyramidal cells (Fig. 6; Table 3). We observed that FS $\rightarrow$ PYR pairs across all age groups exhibited shortterm depression, evident by a decrease in the amplitude of the second IPSC. We did not find developmental change in PPR (PPR, $0.46 \pm 0.05 \%$ at $\mathrm{P} 6-\mathrm{P} 7$ vs $96 \pm$ $0.09 \%$ at P15-P18) (Fig. 6F; Table 3). However, we did observe a significant reduction in IPSC failure rate during development. Unitary FS $\rightarrow$ PYR synapses at P6-P7 exhibited a very high number of failures in contrast to those of more mature pairs, which rarely failed to respond (35.2\% failure rate at $\mathrm{P} 6-\mathrm{P} 7$ vs $4.0 \%$ at $\mathrm{P} 15-\mathrm{P} 18 ; n=6$ pairs tested per age group) (Fig. 6G). These results suggest that the impact of FS cell inhibition on pyramidal cell firing could also be developmentally regulated. Together, our data indicate that pyramidal cell excitability is only weakly regulated by FS cell inhibition during very early development.

\section{Discussion}

Our data support two main conclusions. First, we have shown that functional GABAergic connections among FS cells first appear at P5-6. Second, we demonstrated that electrical connections among FS cells appear at the same time as the GABAergic connections develop.

\section{Development of electrophysiological properties of FS cells}

We found that at P3, FS interneurons are already able to respond to near threshold current injections with high-frequency discharges and subthreshold membrane oscillations, which are characteristic electrophysiological patterns of adult FS cells (Kawaguchi, 1997; Tateno et al., 2004; Towers and Hestrin, 2008; Okaty et al., 2009). We observed significant developmental changes in membrane properties, such as an increase in the frequency of threshold discharges, a decrease in spike width, and a threefold decrease in the input resistance (Fig. 2; Table 1). Similar findings have been shown recently by Okaty et al. (2009), who identified changes in both electrophysiological properties and expression patterns of ion channels in FS cells between P7 and P25.
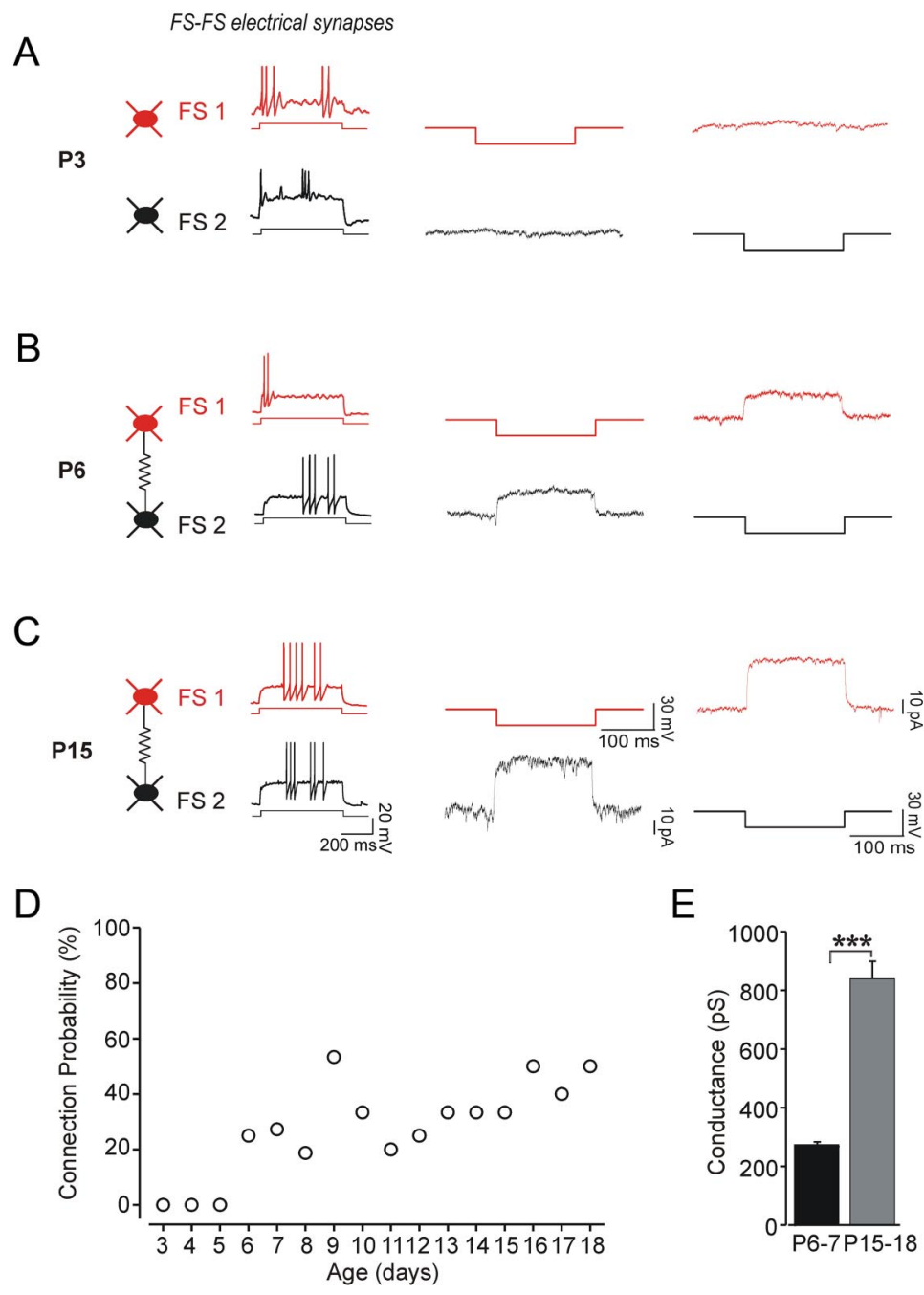

E

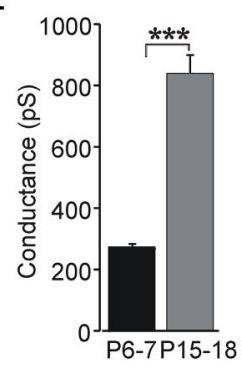

Figure 5. Electrical coupling among FS cells at P3, P6, and P15. The firing patterns of the respective two FS cells are shown on the left. Their paired recordings in voltage clamp are illustrated on the right, where both neurons are held at $-70 \mathrm{mV}$, and a brief the step $(200 \mathrm{~ms}, 30 \mathrm{mV})$ is applied to one cell while recording the current in the other cell. Each trace is the average of 50 trials.

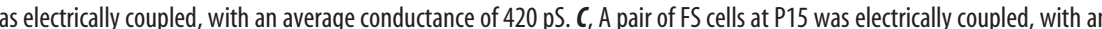
政 $780 \mathrm{pS}$. D. Scatter plot of the connection probability and postnatal age $(n=138$ pairs tested between $P 3$ and P18). $\boldsymbol{E}$, The amplitude of the electrical conductance increased threefold between P5-P7 (onset of connectivity) and P15-P17 ${ }^{* * *} p<0.001 ; n=7-9$ pairs per age group).

\section{Onset of GABAergic synaptic interactions of} fast-spiking interneurons

Local GABAergic connections could play an important role in coordinating neuronal activity, which in turn is thought to affect the organization of functional circuits in the developing cortex (Katz and Shatz, 1996; Ben-Ari, 2001; Ben-Ari et al., 2004; Adelsberger et al., 2005; Cang et al., 2005; Moody and Bosma, 2005; Hanganu et al., 2006). Extracellular stimulation has shown that functional GABAergic synapses are present in the neocortex in the first postnatal week (Luhmann and Prince, 1991; Agmon et al., 1996). The presynaptic elements generating GABA-mediated synaptic responses in the immature cortex may be cortical cells in layers 2- 6 but could also include L1 neurons or ascending axons of inhibitory subplate cells and subcortical GABAergic axons (Schwartz et al., 1998; Dammerman et al., 2000a,b; Dupont et al., 2006). A previous study showed that FS cells in L4 of somatosensory cortex form GABAergic connections with spiny stellate cells around P4 (Daw et al., 2007). However, the onset of GABAergic 

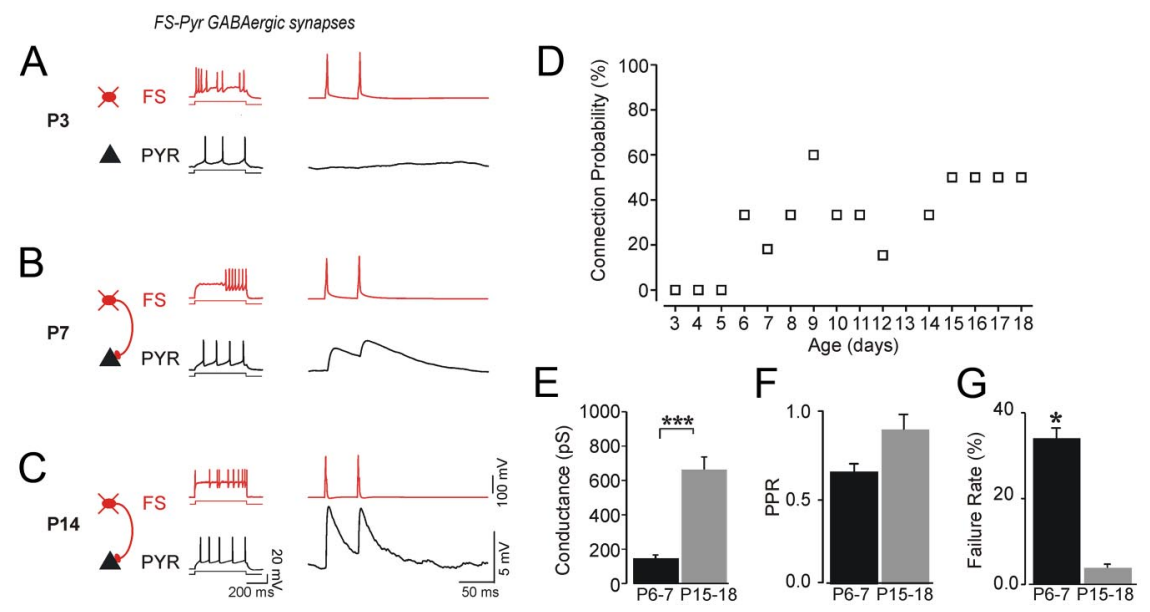

Figure 6. GABAergic connections between pairs of $\mathrm{FS} \rightarrow \mathrm{PRY}$ cells at P3, P7, and P14. A-C, Firing patterns of the respective $\mathrm{FS} \rightarrow$ PYR cells are shown on the left. Paired recordings in current clamp are illustrated on the right, where two brief suprathreshold current injections are applied to the presynaptic FS cell and the response (IPSP) is recorded from the postsynaptic pyramidal cell. Each trace is the average of at least 50 trials. $A$, At P3 we did not detect any GABA-mediated response. $\boldsymbol{B}$, An example of a P7 $\mathrm{FS} \rightarrow$ PYR cell pair connected via an unidirectional GABAergic synapse. $C$, An example of a P14 FS $\rightarrow$ PYR cell pair exhibiting a unidirectional GABAergic IPSPs recorded in the pyramidal cell. $D$, Scatter plot of the connection probability and postnatal age $(n=$ 80 pairs tested). $\boldsymbol{E}$, Plot of GABA conductances show a fourfold increase between P5-P7 (onset of connectivity) and P15-P17 $\left({ }^{* * *} p<0.001 ; n=7\right.$ pairs per age group). $\boldsymbol{F}$, Paired-pulse ratio of the evoked inhibitory postsynaptic current at P5-P7 was not significantly different compared to that at P15-P18. G, The failure rate decreased significantly, from $35.3 \%$ at P6-P7 to $4 \%$ at P15-P18 $\left({ }^{*} p<0.01 ; n=6\right)$. See also Table 3.

connections among FS cells has not been determined previously. Here, we found that GABAergic connections among L5/6 FS cells as well as between L5/6 FS cells and pyramidal cells can first be detected at P5 in the visual cortex of the mouse. Thus, GABAergic connections among FS cells, between FS cells and pyramidal neurons in L5/6, and between FS cells and spiny stellate cells in L4 all appear at about the same developmental period. Furthermore, our data showed that the probability of identifying GABAergic synapses formed by FS cells increased during the next two postnatal weeks. In addition, both synaptic conductance and synaptic reliability increased during cortical maturation. Together, these data suggest that GABAergic synapses formed by FS cells do not contribute to coordinating cortical activity in the perinatal period (before P5). After P4-P5, the probability of connection as well as the strength and reliability of the connections steadily increases, suggesting that their influence on cortical activity increases during the second postnatal week. The decrease in the failure rate could be generated by increased probability of release or from an increase in the number of release sites among FS cells. However, an increase in PPR (Fig. 4B) suggests that the probability of release increases (Zucker and Regehr, 2002). Thus, our findings suggest that during development the number of synaptic contacts among FS cells increases, as reflected in the increased probability of identifying connections and decrease in failure. We have not studied the mechanisms that underlie these changes. However, it is likely that increase in axonal and dendritic length results in increased overlap of axons and dendrites, potentially generating more synaptic contacts. Developmental increase in the number of contacts among FS cells is also suggested by the increased conductances (Fig. 4E). However, we cannot rule out other mechanisms i.e., increase in the number of postsynaptic receptors.

\section{Synaptogenesis of electrical coupling}

It was shown previously that L5 parvalbumin-expressing GABAergic neurons are born early during embryogenesis (Butt et al., 2005; Cobos et al., 2005; Rymar and Sadikot, 2007) and that L5 is already populated with GABAergic neurons on the day of birth (Hevner et al., 2004). In agreement with these data, in the transgenic line we use (G42), EGFP-positive cells are present at P0, and these EGFPpositive cells express parvalbumin in the adult neocortex (Chattopadhyaya et al., 2004). Here we showed that L5/6 FS cells in the visual cortex are not electrically coupled before P5. In addition, we also showed that the magnitude of the conductance among electrically coupled pairs of FS cells is initially half of that we found in older animals. Moreover, we found no electrical coupling between FS cells and pyramidal neurons, suggesting that the process of synaptogenesis of electrical synapses is selective.

The factors controlling synaptogenesis of electrical connections among FS cells are not known. However, growth and maturation of dendrites is likely to be important (Chattopadhyaya et al., 2004). Moreover, studies of connexin-36 (Cx36), which underlies electrical coupling among FS cells (Deans et al., 2001), have shown that Cx36 expression is sparse at birth and increases during development peaking at P14 (Belluardo et al., 2000) suggesting that expression of Cx36 may play a role in synaptogenesis of electrical synapses. Those data, together with our physiological studies, indicate that PV-FS cells are present in L5 after birth but do not form functional electrical synapses before P5. The onset of electrical coupling among a different type of inhibitory neuron, the low-threshold spiking (LTS) cell, has not been determined previously. However, it was shown that the incidence of electrical coupling among neocortical LTS cells does not change between P8 and P15 (Long et al., 2005). These observations are generally similar to our finding (Fig. 5). It will be interesting to investigate when LTS cells form electrical synapses. Recent studies have found that inhibitory neurons in thalamic reticular nucleus are extensively electrically coupled in P1 mice and that the incidence of coupling does not change during maturation (Parker et al., 2009). In addition, it was reported that thalamic relay cells are connected by electrical synapses in P2 mice and that during maturation electrical coupling disappears (Lee et al., 2010). These data suggest that the developmental time course of electrical coupling varies among different brain regions.

Previous work has shown that the incidence of dye coupling among neocortical neurons in rodents is high after birth and declines dramatically after P14 (Connors et al., 1983; Peinado et al., 1993b). These data can be interpreted as an indication that electrical coupling is generally prevalent among different types of cortical neurons during the early postnatal period (Peinado et al., 1993a; Peinado, 2001; Montoro and Yuste, 2004; Sutor and Hagerty, 2005). However, without direct demonstration of electrical synapses, quantitative interpretation of dye-coupling experiments is difficult (Connors and Long, 2004; Wang et al., 2010). In juveniles and adults, FS cells have been shown to be extensively interconnected by gap junctions (Connors and Long, 2004; Hestrin and Galarreta, 2005). Our results, using paired recording, demonstrate that FS cells do not form electrical syn- 
apses before P5. In addition, we have not found electrical coupling among L5/6 pyramidal cells in immature animals. It is thus attractive to speculate that electrical coupling is rare among other types of cortical neurons in newborn mice. Further experiments using paired recording among other types of cortical neurons will resolve this issue. Interestingly, paired recordings have shown that a subset of subplate neurons are electrically coupled (Dupont et al., 2006). Together, these data suggest that electrical coupling plays a role in generating network activity in the subplate but not in the cortical layers of newborn animals.

\section{Conclusion}

We did not identify electrical or chemical synaptic interactions of FS cells before P5. These data indicate that the spatiotemporal patterns that are observed in the early postnatal days in mice are not generated by FS cells. We did not record from FS cells in layers $2-4$. However, layer 5/6 develops before layers $2-4$, and it is thus likely that FS cells in those layers do not contribute to patterned activity either. Several studies have shown that network activity in the developing neocortex changes around the end of the first postnatal week in rodents (Garaschuk et al., 2000; Dupont et al., 2006; Allene et al., 2008; Yang et al., 2009). Our data suggest that the synaptogenesis of both electrical and GABAergic connections of FS cells plays a role in the transition of network activity occurring at the end of the first postnatal week (Garaschuk et al., 2000; Moody and Bosma, 2005; Allene et al., 2008; Yang et al., 2009).

\section{References}

Adelsberger H, Garaschuk O, Konnerth A (2005) Cortical calcium waves in resting newborn mice. Nat Neurosci 8:988-990.

Agmon A, Hollrigel G, O’Dowd DK (1996) Functional GABAergic synaptic connection in neonatal mouse barrel cortex. J Neurosci 16:4684-4695.

Allene C, Cattani A, Ackman JB, Bonifazi P, Aniksztejn L, Ben-Ari Y, Cossart $\mathrm{R}$ (2008) Sequential generation of two distinct synapse-driven network patterns in developing neocortex. J Neurosci 28:12851-12863.

Bartos M, Vida I, Frotscher M, Meyer A, Monyer H, Geiger JR, Jonas P (2002) Fast synaptic inhibition promotes synchronized gamma oscillations in hippocampal interneuron networks. Proc Natl Acad Sci U S A 99:13222-13227.

Bartos M, Vida I, Jonas P (2007) Synaptic mechanisms of synchronized gamma oscillations in inhibitory interneuron networks. Nat Rev Neurosci 8:45-56.

Belluardo N, Mudo G, Trovato-Salinaro A, Le Gurun S, Charollais A, SerreBeinier V, Amato G, Haefliger JA, Meda P, Condorelli DF (2000) Expression of connexin 36 in the adult and developing rat brain. Brain Res 865:121-138.

Ben-Ari Y (2001) Developing networks play a similar melody. Trends Neurosci 24:353-360.

Ben-Ari Y, Khalilov I, Represa A, Gozlan H (2004) Interneurons set the tune of developing networks. Trends Neurosci 27:422-427.

Butt SJ, Fuccillo M, Nery S, Noctor S, Kriegstein A, Corbin JG, Fishell G (2005) The temporal and spatial origins of cortical interneurons predict their physiological subtype. Neuron 48:591-604.

Cang J, Renteria RC, Kaneko M, Liu X, Copenhagen DR, Stryker MP (2005) Development of precise maps in visual cortex requires patterned spontaneous activity in the retina. Neuron 48:797-809.

Cardin JA, Carlen M, Meletis K, Knoblich U, Zhang F, Deisseroth K, Tsai LH, Moore CI (2009) Driving fast-spiking cells induces gamma rhythm and controls sensory responses. Nature 459:663-667.

Chattopadhyaya B, Di Cristo G, Higashiyama H, Knott GW, Kuhlman SJ, Welker E, Huang ZJ (2004) Experience and activity-dependent maturation of perisomatic GABAergic innervation in primary visual cortex during a postnatal critical period. J Neurosci 24:9598-9611.

Cobos I, Calcagnotto ME, Vilaythong AJ, Thwin MT, Noebels JL, Baraban SC, Rubenstein JL (2005) Mice lacking Dlx1 show subtype-specific loss of interneurons, reduced inhibition and epilepsy. Nat Neurosci 8:1059-1068.
Connors BW, Long MA (2004) Electrical synapses in the mammalian brain. Annu Rev Neurosci 27:393-418.

Connors BW, Benardo LS, Prince DA (1983) Coupling between neurons of the developing rat neocortex. J Neurosci 3:773-782.

Dammerman RS, Noctor SC, Kriegstein AR (2000a) Extrinsic GABAergic innervation of developing neocortical layer 1 in organotypic slice cocultures. J Comp Neurol 423:112-120.

Dammerman RS, Flint AC, Noctor S, Kriegstein AR (2000b) An excitatory GABAergic plexus in developing neocortical layer 1. J Neurophysiol 84:428-434.

Daw MI, Ashby MC, Isaac JT (2007) Coordinated developmental recruitment of latent fast spiking interneurons in layer IV barrel cortex. Nat Neurosci 10:453-461.

Deans MR, Gibson JR, Sellitto C, Connors BW, Paul DL (2001) Synchronous activity of inhibitory networks in neocortex requires electrical synapses containing connexin36. Neuron 31:477-485.

Dupont E, Hanganu IL, Kilb W, Hirsch S, Luhmann HJ (2006) Rapid developmental switch in the mechanisms driving early cortical columnar networks. Nature 439:79-83.

Galarreta M, Hestrin S (1999) A network of fast-spiking cells in the neocortex connected by electrical synapses. Nature 402:72-75.

Galarreta M, Hestrin S (2002) Electrical and chemical synapses among parvalbumin fast-spiking GABAergic interneurons in adult mouse neocortex. Proc Natl Acad Sci U S A 99:12438-12443.

Galarreta M, Erdelyi F, Szabo G, Hestrin S (2008) Cannabinoid sensitivity and synaptic properties of 2 GABAergic networks in the neocortex. Cereb Cortex 18:2296-2305.

Garaschuk O, Linn J, Eilers J, Konnerth A (2000) Large-scale oscillatory calcium waves in the immature cortex. Nat Neurosci 3:452-459.

Gibson JR, Beierlein M, Connors BW (1999) Two networks of electrically coupled inhibitory neurons in neocortex. Nature 402:75-79.

Hanganu IL, Ben-Ari Y, Khazipov R (2006) Retinal waves trigger spindle bursts in the neonatal rat visual cortex. J Neurosci 26:6728-6736.

Hestrin S, Galarreta M (2005) Electrical synapses define networks of neocortical GABAergic neurons. Trends Neurosci 28:304-309.

Hevner RF, Daza RA, Englund C, Kohtz J, Fink A (2004) Postnatal shifts of interneuron position in the neocortex of normal and reeler mice: evidence for inward radial migration. Neuroscience 124:605-618.

Jefferys JG, Traub RD, Whittington MA (1996) Neuronal networks for induced "40 Hz" rhythms. Trends Neurosci 19:202-208.

Katz LC, Shatz CJ (1996) Synaptic activity and the construction of cortical circuits. Science 274:1133-1138.

Kawaguchi Y (1997) Selective cholinergic modulation of cortical GABAergic cell subtypes. J Neurophysiol 78:1743-1747.

Kawaguchi Y, Kubota Y (1997) GABAergic cell subtypes and their synaptic connections in rat frontal cortex. Cereb Cortex 7:476-486.

Klausberger T, Magill PJ, Marton LF, Roberts JD, Cobden PM, Buzsaki G, Somogyi P (2003) Brain-state- and cell-type-specific firing of hippocampal interneurons in vivo. Nature 421:844-848.

Lee SC, Cruikshank SJ, Connors BW (2010) Electrical and chemical synapses between relay neurons in developing thalamus. J Physiol 588:2403-2415.

Long MA, Cruikshank SJ, Jutras MJ, Connors BW (2005) Abrupt maturation of a spike-synchronizing mechanism in neocortex. J Neurosci 25:7309-7316.

Luhmann HJ, Prince DA (1991) Postnatal maturation of the GABAergic system in rat neocortex. J Neurophysiol 65:247-263.

Meyer AH, Katona I, Blatow M, Rozov A, Monyer H (2002) In vivo labeling of parvalbumin-positive interneurons and analysis of electrical coupling in identified neurons. J Neurosci 22:7055-7064.

Montoro RJ, Yuste R (2004) Gap junctions in developing neocortex: a review. Brain Res Brain Res Rev 47:216-226.

Moody WJ, Bosma MM (2005) Ion channel development, spontaneous activity, and activity-dependent development in nerve and muscle cells. Physiol Rev 85:883-941.

Okaty BW, Miller MN, Sugino K, Hempel CM, Nelson SB (2009) Transcriptional and electrophysiological maturation of neocortical fastspiking GABAergic interneurons. J Neurosci 29:7040-7052.

Parker PR, Cruikshank SJ, Connors BW (2009) Stability of electrical coupling despite massive developmental changes of intrinsic neuronal physiology. J Neurosci 29:9761-9770.

Peinado A (2001) Immature neocortical neurons exist as extensive syn- 
citial networks linked by dendrodendritic electrical connections. J Neurophysiol 85:620-629.

Peinado A, Yuste R, Katz LC (1993a) Gap junctional communication and the development of local circuits in neocortex. Cereb Cortex 3:488-498.

Peinado A, Yuste R, Katz LC (1993b) Extensive dye coupling between rat neocortical neurons during the period of circuit formation. Neuron 10:103-114.

Pouzat C, Hestrin S (1997) Developmental regulation of basket/stellate cell $\rightarrow$ Purkinje cell synapses in the cerebellum. J Neurosci 17:9104-9112.

Rymar VV, Sadikot AF (2007) Laminar fate of cortical GABAergic interneurons is dependent on both birthdate and phenotype. J Comp Neurol 501:369-380.

Schwartz TH, Rabinowitz D, Unni V, Kumar VS, Smetters DK, Tsiola A, Yuste R (1998) Networks of coactive neurons in developing layer 1. Neuron 20:541-552.

Sohal VS, Zhang F, Yizhar O, Deisseroth K (2009) Parvalbumin neurons and gamma rhythms enhance cortical circuit performance. Nature 459:698-702.

Sutor B, Hagerty T (2005) Involvement of gap junctions in the development of the neocortex. Biochim Biophys Acta 1719:59-68.
Tateno T, Harsch A, Robinson HP (2004) Threshold firing frequencycurrent relationships of neurons in rat somatosensory cortex: type 1 and type 2 dynamics. J Neurophysiol 92:2283-2294.

Towers SK, Hestrin S (2008) D1-like dopamine receptor activation modulates GABAergic inhibition but not electrical coupling between neocortical fast-spiking interneurons. J Neurosci 28:2633-2641.

Uematsu M, Hirai Y, Karube F, Ebihara S, Kato M, Abe K, Obata K, Yoshida S, Hirabayashi M, Yanagawa Y, Kawaguchi Y (2008) Quantitative chemical composition of cortical GABAergic neurons revealed in transgenic venus-expressing rats. Cereb Cortex 18:315-330.

Venance L, Rozov A, Blatow M, Burnashev N, Feldmeyer D, Monyer H (2000) Connexin expression in electrically coupled postnatal rat brain neurons. Proc Natl Acad Sci U S A 97:10260-10265.

Wang Y, Barakat A, Zhou H (2010) Electrotonic coupling between pyramidal neurons in the neocortex. PLoS One 5:e10253.

Yang JW, Hanganu-Opatz IL, Sun JJ, Luhmann HJ (2009) Three patterns of oscillatory activity differentially synchronize developing neocortical networks in vivo. J Neurosci 29:9011-9025.

Zucker RS, Regehr WG (2002) Short-term synaptic plasticity. Annu Rev Physiol 64:355-405. 